\title{
PERMAINAN PUZZLE MEMPENGARUHI PERKEMBANGAN KECERDASAN VISUAL-SPATIAL ANAK USIA 4-5 TAHUN DI TK AL-FATH DESA KEBOAN ANOM GEDANGAN SIDOARJO
}

\author{
Devi Ayu Anjani ${ }^{*}$, Siti Nurjanah ${ }^{* *}$ \\ UNUSA, Fakultas Keperawatan dan Kebidanan - J1. SMEA 57 Surabaya \\ Email: nurjanah@unusa.ac.id
}

\begin{abstract}
One of the Visual-spatial intelligence development of children aged 4-5 years is a child can recognize up to 12 kinds of colours, in fact it is still found children aged 4-5 are not able to recognize colours properly. From preliminary data obtained $35.4 \%$ of children aged 4-5 years in visual-spatial intelligence development of children, they were not able to recognize colours properly. The purpose of this study was to determine the effect of a puzzle game on visual-spatial intelligence development of children aged 4-5 years. This study was conducted in Al-Fath kindergarten. Study design use pre experimental with one group pretest-posttest design. The population were children aged 45 years in kindergarten Al-Fath by 150 children with 30 respondents taken by simple random sampling. Independent variable is puzzle game and the dependent variable is the development of children's visual-spatial intelligence. Data were collected use observation sheets then analyzed by statistically test of paired sample t test with significance level $\alpha$ $<0.05$. The results showed there is an increasing (13.4\%) very good and (20\%) good of visual-spatial intelligence after giving intervention. Obtained $\rho=0.000<\alpha=0.05$ so $\mathbf{H}_{0}$ rejected, which means there is a puzzle game influence on the development of visualspatial intelligence of children aged 4-5 years in kindergarten Al-Fath Keboan Anom village Gedangan Sidoarjo. From study results concluded that the puzzle can be used as a medium of learning to improve children's visual-spatial intelligence. It is recommended to use puzzle and parents can facilitate educational games for children and accompany them.
\end{abstract}

\begin{abstract}
ABSTRAK : Perkembangan kecerdasan visual-spatial anak usia 4-5 tahun salah satunya adalah anak dapat mengenal warna hingga 12 warna, kenyataannya anak usia 4-5 tahun masih ada yang belum dapat mengenal warna dengan benar. Didapatkan dari data awal yang menunjukkan bahwa perkembangan kecerdasan visualspatial anak usia 4-5 tahun 35,4\% anak belum tepat dalam penggunaan warna. Tujuan penelitian ini adalah mengetahui pengaruh permainan puzzle terhadap perkembangan kecerdasan visual-spatial anak usia 4-5 tahun. Studi dilakukan di TK Al-Fath. Desain penelitian menggunakan metode dengan jenis rancangan preexperiment design yaitu the one group pretest-posttest design. Populasi penelitian ini adalah anak usia 4-5 tahun di TK Al-Fath sebanyak 150 responden dengan sampel 30 responden dan mengunakan simple random sampling. Variable independent yaitu permainan puzzle dan variable dependent yaitu perkembangan kecerdasan visual-spatial anak. Pengumpulan data mengunakan lembar observasi kemudian di analisis menggunakan uji statistik uji t sampel berpasangan dengan tingkat kemaknaan $\alpha<0,05$. Hasil penelitian menunjukkan bahwa terjadi kenaikan sebesar $(13,4 \%)$ kecerdasan visual-spatial sangat baik sesudah dilakukan intervensi dan (20\%) kecerdasan visual-spatial baik sesudah dilakukan intervensi. Didapatkan $\rho=0.000<$ $\alpha=0.05$ maka $\mathbf{H}_{0}$ ditolak yang berarti ada pengaruh permainan puzzle terhadap perkembangan kecerdasan visual-spatial anak usia 4-5 tahun di TK Al-Fath Desa Keboan
\end{abstract}


Anom Gedangan Sidoarjo. Dari hasil penelitian ini disimpulkan bahwa permainan puzzle dapat dimanfaatkan sebagai media pembelajaran untuk mengasah kecerdasan visual-spatial anak. Disarankan agar puzzle dimanfaatkan dengan baik dan orang tua dapat menfasilitasi permainan edukatif untuk anak serta mendampingi mereka saat bemain.

Kata kunci : permainan puzzle, perkembangan kecerdasan visual-spatial

\section{PENDAHULUAN}

Kecerdasan adalah kapasitas untuk menyelesaikan masalah-masalah dan membuat cara penyelesaiannya dalam konteks yang beragam dan wajar (Sefrina, 2013). Kecerdasan manusia dipengaruhi oleh informasi-informasi sekitar mereka. Pada anak, 95\% informasi yang didapat berasal dari penglihatan, sentuhan dan pendengaran (Greene, 2005). Sebelum anak dapat berbicara, maka ia akan melakukan pengamatan sendiri dengan cara melihat objek dan memegang. Dalam proses ini saraf peraba dan saraf visual anak bekerja untuk memahami bentuk-bentuk tertentu (Surya, 2007). Inilah awal mula dari kecerdasan visual-spatial. Kecerdasan visual-spatial adalah kemampuan memahami, memproses, dan berpikir dalam bentuk visual dan mencitrakannya dalam bentuk dua atau tiga dimensi.

Perkembangan kecerdasan visualspatial anak usia 4-5 tahun adalah mampu mengenal 12 warna; dapat bermain puzzle tiga dimensi atau dua dimensi hingga 20 keping; dapat dikenalkan dengan segi yang lebih rumit seperti segi tujuh (heptagon) sampai segi sepuluh; dapat menggambar manusia minimal 3 bagian tubuh manusia; dapat memahami semua konsep arah dan posisi, dapat memahami konsep bilangan dan konsep ukuran (Surya, 2007).

Menurut penelitian Sri Utami pada tahun 2008 di TK Pertiwi Dharma Wanita Trenggalek menunjukkan bahwa dari 38 anak, 21,4\% belum dapat mengenal konsep bilangan dan menyebut bentuk-bentuk geometri dengan baik, $14,3 \%$ belum mampu mengelompokkan benda sesuai warna, bentuk, maupun ukuran, $17,9 \%$ belum mampu menggambar lingkaran dan bujur sangkar dan $28,6 \%$ belum dapat membuat perkiraan urutan suatu benda (Jurnal Ners Vol.3, 2008).

Berdasarkan penilaian bulan Desember 2013 pada anak usia 4-5 tahun di TK Al-Fath Desa Keboan Anom Gedangan Sidoarjo didapatkan dari 48 kuesioner yang disebar, $100 \%$ anak belum dapat menggambar manusia minimal 3 bagian tubuh manusia dan $8,3 \%$ anak belum dapat melengkapi gambar dengan benar. Dari 5 bentuk geometri yang ditunjukan yang terdiri dari segitiga, trapesium, persegi, lingkaran dan setengah lingkaran, hanya 1 bentuk geometri yang tidak dimengerti yaitu trapesium. Dari 6 gambar yang ditunjukkan yaitu strawberry dengan standart warna merah, pisang dengan standart warna kuning, jeruk dengan standart warna orange, daun dengan standart warna hijau tua, awan dengan standart warna biru muda dan tikus dengan standart warna coklat tua didapatkan hasil $64,6 \%$ anak sudah tepat dalam penggunaan warna dan $35,4 \%$ anak belum tepat dalam penggunaan warna. Dari hasil pengamatan tersebut dapat disimpulkan bahwa kecerdasan visual-spatial anak di TK Al-Fath kurang.

Menurut Kamus Besar Bahasa Indonesia (2005), puzzle adalah "tekateki”. Menurut Hamalik tahun 1980, gambar adalah sesuatu yang diwujudkan secara visual dalam bentuk dua dimensi sebagai curahan perasaan dan pikiran. Oleh karena itu, media puzzle merupakan media gambar yang termasuk ke dalam 
media visual karena hanya dapat dicerna melalui indera penglihatan saja.

Puzzle merupakan permainan yang membutuhkan kesabaran dan ketekunan anak dalam merangkainya. Puzzle merupakan kepingan tipis yang terdiri dari 2-3 bahkan 4-6 potongyang terbuat dari kayu atau lempeng karton. Dengan terbiasa bermain puzzle, lambat laun mental anak juga akan terbiasa untuk bersikap tenang, tekun, dan sabar dalam menyelesaikan sesuatu. Kepuasan yang didapat saat anak menyelesaikan puzzle pun merupakan salah satu pembangkit motivasi anak untuk menemukan hal-hal yang baru.

Manfaat puzzle sebagai media bermain (Abdulloh, 2012) :

a. Meningkatkan keterampilan kognitif

Keterampilan kognitif berhubungan dengan kemampuan untuk belajar dan memecahkan masalah. Melalui puzzle, anak-anak akan mencoba memecahkan masalah yaitu menyusun gambar menjadi utuh.

b. Meningkatkan keterampilan motorik halus

Anak dapat melatih koordinasi tangan dan mata untuk mencocokkan kepingankepingan puzzle dan menyusunnya menjadi satu gambar. Keterampilan motorik halus berhubungan dengan kemampuan anak menggunakan otot-otot kecilnya khususnya jari-jari tangannya.

c. Melatih kemampuan nalar dan daya ingat dan konsentrasi

Puzzle yang berbentuk manusia akan melatih nalar anak-anak. Melalui puzzle ini mereka akan menyimpulkan di mana letak tangan, kaki, dan lain-lain sesuai dengan logika. Saat bermain puzzle, anak akan melatih sel-sel otaknya untuk mengembangkan kemampuan berpikirnya dan berkonsentrasi untuk menyelesaikan potongan-potongan kepingan gambar tersebut.

d. Pengetahuan melalui puzzle

Anak akan belajar banyak hal. Mulai dari warna, bentuk, jenis hewan, buahbuahan, sayuran dan lainnya.
Pengetahuan yang ia dapatkan dari sebuah permainan biasanya akan lebih mengesankan bagi anak dibandingkan pengetahuan yang ia dapatkan dari hafalan.

e. Meningkatkan keterampilan sosial

Puzzle dapat dimainkan lebih dari satu orang dan jika puzzle dimainkan secara berkelompok tentunya butuh diskusi untuk merancang kepingankepingan gambar dari puzzle tersebut, maka hal ini akan meningkatkan interaksi sosial anak.

Kecerdasan visual-spatial adalah kemampuan memahami, memproses, dan berpikir dalam bentuk visual. Seseorang dengan kecakapan ini mampu menerjemahkan bentuk gambaran dalam pikirannya ke dalam bentuk dua atau tiga dimensi.

Inti dari kecerdasan ini adalah kapasitas seseorang untuk memahami apa yang ia lihat secara akurat, membuat perubahan dan memodifikasi dari hasil pemahaman/persepsi visual tersebut, serta kemampuan untuk membangun kembali apa yang telah dilihat meski tidak ada rangsangan lagi/tidak ada objek yang dilihat lagi (Sefrina, 2013).

Seorang ahli psikologi bernama Thurstone mengungkapkan bahwa kemampuan kita akan memahami ruang dan objek dibagi menjadi 3 komponen yaitu kemampuan untuk mengenali objek atau suatu benda meski dilihat dari sisi yang berberda, kemampuan untuk mengimajinasikan pergerakan objek atau mengenali bagian-bagian dari suatu objek atau benda, dan kemampuan untuk menghubungkan objek dan ruang yang berorientasi pada diri individu yang melihat objek dan ruang tersebut.

Ciri-ciri kecerdasa Visual-Spatal Usia 4-6 tahun

a) Mampu mengenal 12 warna.

b) Dapat bermain puzzle tiga dimensi atau puzzle dua dimensi hingga 20 keping.

c) Sudah dapat dikenalkan dengan bentuk segi yang lebih rumit, 
misalnya segi tujuh (heptagon) sampai segi sepuluh.

d) Sudah memahami semua konsep arah dan posisi seperti kanan-kiri, atasbawah, depan-belakang, majumundur, lurus-belok.

e) Sudah memahami konsep jumlah (banyak-sedikit) dan konsep ukuran (besar-kecil, panjang-pendek).

Menurut penelitian Philip Morrow tahun 2005, bermain puzzle terbukti bisa meningkatkan keterampilan berlatih otak kita. Riset ini dilakukan pada sekitar 15 orang yang sukarela setiap hari hanya dalam waktu seminggu. Sebelumnya para peneliti berharap bisa meningkatkan kecerdasan mereka sampai sekitar 10\%, namun alangkah mengejutkan setelah riset berakhir, seluruh responden mencatat kenaikan sampai sekitar 40\% (Winsky, 2009).

\section{METODE PENELITIAN}

Desain penelitian menggunakan metode dengan jenis rancangan preexperiment design yaitu the one group pretest-posttest design. Populasi penelitian ini adalah anak usia 4-5 tahun di TK Al-Fath sebanyak 150 responden dengan sampel 30 responden dan mengunakan simple random sampling. Variable independent yaitu permainan puzzle dan variable dependent yaitu perkembangan kecerdasan visual-spatial anak. Dalam penelitian ini instrumen yang digunakan baik untuk variabel dependent adalah lembar observasi berbentuk checklist.

Langkah pertama dalam pengumpulan data penelitian ini adalah mengajukan permohonan penelitian dari UNUSA kepada TK Al-Fath Desa Keboan Anom Gedangan Sidoarjo, kemudian peneliti melakukan pendekatan kepada guru dan siswa TK. Responden diberi intervensi permainan jigsaw puzzle tiap individu dengan frekuensi setiap hari dalam 30 menit selama 1 minggu. Setiap responden memilih sendiri permainan puzzle yang akan mereka mainkan. Pada pertemuan ke 6 , peneliti melakukan posttest dengan observasi perkembangan kecerdasan visual-spatial anak melalui lembar observasi yang telah dibuat oleh peneliti.

\section{HASIL}

Hasil data khusus berisi karakteristik responden yang meliputi kecerdasan visual-spatial responden berdasarkan hasil sebelum diberi permainan puzzle, kecerdasan visual-spatial responden berdasarkan hasil setelah diberi permainan puzzle, Hubungan Permainan Puzzle dengan Perkembangan Kecerdasan Visual-Spatial, analisis perkembangan kecerdasan visual-spatial akibat permainan puzzle

a. Kecerdasan visual-spatial responden berdasarkan hasil sebelum diberi permainan puzzle

Tabel 5.3 Distribusi frekuensi kecerdasan visual-spatial responden berdasarkan hasil sebelum diberi permainan puzzle anak usia 4-5 tahun di TK Al-Fath Desa Keboan Anom Gedangan Sidoarjo tahun 2014

\begin{tabular}{ccc}
\hline \multirow{2}{*}{ Kriteria } & \multicolumn{2}{c}{ Jumlah } \\
\cline { 2 - 3 } & Frekuensi (n) & Persentase (\%) \\
\hline Sangat Baik & 1 & 3.3 \\
Baik & 19 & 63.3 \\
Cukup & 10 & 33.3 \\
Kurang & 0 & 0 \\
Sangat & 0 & 0 \\
Kurang & & \\
\hline Jumlah & 30 & 100 \\
\hline
\end{tabular}

Sumber : Data Primer 2014

Berdasarkan tabel 5.3 dapat diketahui bahwa dari 30 responden dalam penelitian ini sebagian besar anak memiliki kecerdasan Visual-Spatial yang baik sebelum diberi perlakuan.

b. Kecerdasan visual-spatial responden berdasarkan hasil setelah diberi permainan puzzle

Tabel 5.4 Distribusi frekuensi kecerdasan visual-spatial responden berdasarkan hasil setelah diberi permainan puzzle anak usia 4-5 tahun 
di TK Al-Fath Desa Keboan Anom Gedangan Sidoarjo tahun 2014

\begin{tabular}{ccc}
\hline Kriteria & \multicolumn{2}{c}{ Jumlah } \\
\cline { 2 - 3 } & Frekuensi (n) & Persentase (\%) \\
\hline Sangat & 5 & 16.7 \\
Baik & & \\
Baik & 25 & 83.3 \\
Cukup & 0 & 0 \\
Kurang & 0 & 0 \\
Sangat & 0 & 0 \\
Kurang & & \\
\hline Jumlah & 30 & 100
\end{tabular}

Sumber : Data Primer 2014

Berdasarkan tabel 5.4 dapat diketahui bahwa dari 30 responden dalam penelitian ini hampir seluruhnya anak memiliki kecerdasarn Visual-Spatial yang baik setelah diberi perlakuan.

c. Hubungan Permainan Puzzle dengan

Perkembangan Kecerdasan VisualSpatial

Tabel 5.5 Distribusi Kecerdasan VisualSpatial sebelum dan sesudah diberikan permainan puzzle anak usia 4-5 tahun di TK AlFath Desa Keboan Anom Gedangan Sidoarjo tahun 2014

\begin{tabular}{|c|c|c|c|c|c|c|c|c|c|c|c|c|}
\hline \multirow{3}{*}{$\begin{array}{l}\text { Perm } \\
\text { Puzzle }\end{array}$} & \multicolumn{10}{|c|}{ Kecerdasan Visual-Spatial } & \multirow{2}{*}{\multicolumn{2}{|c|}{ Jml }} \\
\hline & \multicolumn{2}{|c|}{ SB } & \multicolumn{2}{|c|}{$\mathrm{B}$} & \multicolumn{2}{|c|}{$\mathrm{C}$} & \multicolumn{2}{|c|}{$\mathrm{K}$} & \multicolumn{2}{|c|}{ SK } & & \\
\hline & $\mathrm{n}$ & $\%$ & $\mathrm{~N}$ & $\%$ & $\mathrm{n}$ & $\%$ & $\mathrm{~N}$ & $\%$ & $\mathrm{n}$ & $\%$ & $\mathrm{n}$ & $\%$ \\
\hline Sbl & 1 & $\begin{array}{l}3 \\
3 \\
3\end{array}$ & $\begin{array}{l}1 \\
9\end{array}$ & $\begin{array}{l}3 \\
3\end{array}$ & $\begin{array}{l}1 \\
0\end{array}$ & $\begin{array}{l}3 \\
3\end{array}$ & 0 & 0 & 0 & 0 & $\begin{array}{l}3 \\
0\end{array}$ & $\begin{array}{l}1 \\
0\end{array}$ \\
\hline Ssd & 5 & $\begin{array}{l}1 \\
6 \\
.\end{array}$ & $\begin{array}{l}2 \\
5\end{array}$ & $\begin{array}{l}8 \\
3\end{array}$ & 0 & $\begin{array}{l}0 \\
. \\
0\end{array}$ & 0 & 0 & 0 & 0 & $\begin{array}{l}3 \\
0\end{array}$ & $\begin{array}{l}1 \\
0\end{array}$ \\
\hline
\end{tabular}

Sumber : Data Primer 2014

Berdasarkan tabel 5.5 dari 30 responden yang diberi test sebelum perlakuan, kecerdasan Visual-spatial sangat baik (3.3\%), kecerdasan Visualspatial baik $(63.3 \%)$ dan kecerdasan Visual-spatial cukup (33.3\%). Kemudian setelah diberi perlakuan berupa permainan Puzzle dalam seminggu hasilnya kecerdasan Visual-spatial sangat baik menjadi (16.7\%) artinya terjadi peningkatan antara sebelum dilakukan perlakuan dengan sesudah diberi perlakuan, kecerdasan Visual- spatial baik menjadi $(83,3 \%)$ dan kecerdasan Visual-spatial cukup menurun menjadi $(0 \%)$.

Tabel $5.6 \quad$ Distribusi analisis perkembangan kecerdasan visual-spatial akibat permainna puzzle anak usia 4-5 tahun di TK Al-Fath Desa Keboan Anom Gedangan Sidoarjo tahun 2014

\begin{tabular}{|c|c|c|c|c|}
\hline \multicolumn{3}{|c|}{ Variabel } & \multirow[b]{2}{*}{$\mathrm{P}$} & \multirow[b]{2}{*}{$\begin{array}{c}\text { Keteranga } \\
n\end{array}$} \\
\hline $\mathrm{N}$ & Dependen & $\begin{array}{l}\text { Independe } \\
n\end{array}$ & & \\
\hline $\begin{array}{l}3 \\
0\end{array}$ & $\begin{array}{c}\text { Permaina } \\
\text { n Puzzle }\end{array}$ & $\begin{array}{c}\text { Kecerdasa } \\
\text { n Visual- } \\
\text { Spatial }\end{array}$ & $\begin{array}{c}0,0 \\
0\end{array}$ & $\begin{array}{c}\text { Ada } \\
\text { perubahan }\end{array}$ \\
\hline
\end{tabular}

Sumber : Data Primer 2014

Berdasarkan uji statistik uji t sampel berpasangan menggunakan SPSS For Windows dengan tingkat kemaknaan $(\alpha=0.05)$ diperoleh nilai $\rho=0.000$ maka $\rho<\alpha$, sehingga $\mathrm{H}_{0}$ ditolak berarti ada pengaruh permainan puzzle terhadap perkembangan kecerdasan visual-spatial anak usia 4-5 tahun di TK Al-Fath Desa Keboan Anom Gedangan Sidoarjo.

Kondisi awal anak d TK Al-Fath sebelum diberikan intervesi mereka belum memahami tentang warna-warna, bentuk-bentuk geometri dan konsep besar kecil. Pada hari pertama intervensi semua anak antusias bermain puzzle. Sebagian besar dari mereka memilih sendiri gambar yang yang akan mereka mainkan. Namun ada 1 anak (An. S) yang tidak meyentuh puzzle nya sama sekali. Anakanak diberi waktu 30 menit untuk menyelesaikan permainan puzzle. Pada hari ke-2 anak masih tetap antusias untuk permainan puzzle. Mereka memilih sendiri gambar yang akan mereka mainkan. Anak yang kemarin (An. S) masih belum mau menyentuh permainan puzzle nya. Namun anak-anak yang lain mendukungnya agar dia dapat menyelesaikan permainan puzzle nya. Beberapa menit kemudian ada 2 anak yang menangis karena di ejek temannya 
dan mereka tidak mau menyelesaikan permainannya.

Pada hari ke-3 hanya berjumlah 27 anak, 3 anak tidak mengikuti intervensi karena di ajak pulang oleh orang tuanya. Anak-anak masih tetap antusias. An. S mulai mau menyelesaikan permainannya dibantu oleh teman-temannya. Ada 2 anak yang masih meminta bantuan kepada guru dan peneliti. Pada hari ke-4 berjumlah 29 anak, 1 anak tidak masuk karena sakit. Anak-anak mulai bosan dengan permainan puzzle, tetapi peneliti berhasil membujuk dibantu oleh guru. Beberapa menit kemudian 5 anak pulang diajak oleh orang tuanya sehingga mereka tidak menyelesaikan permainan puzzle nya.

Pada hari ke-5 peneliti mensiasati dengan memberikan hadiah bagi anak yang mau bermain puzzle dengan cepat dan tepat. Anak-anak pun kembali antusias dan berlomba-lomba untuk menyelesaikan puzzle. Peneliti memberikan pengertian kepada wali murid yang ingin mengajak anaknya pulang. Pada hari ke-6 peneliti melakukan posttest hasil perkembangan kecerdasan visual-spatial anak yang telah diberi permainan puzzle.

\section{PEMBAHASAN}

Berdasarkan tabel 5.3 dapat diketahui bahwa dari 30 responden dalam penelitian ini sebelum dilakukan intervensi berupa permainan puzzle (3.3\%) responden memiliki kecerdasan visual-spatial yang sangat baik. Hal ini disebabkan karena anak tersebut memanfaatkan otak kanannya dengan baik (kidal).

Sebagian besar responden (63.3\%) memiliki kecerdasan Visual-Spatial yang baik dalam arti mereka dapat menyelesaikan permainan puzzle dengan benar namun dalam kurun waktu yang cukup lama. Mereka juga dapat menyebutkan bentuk-bentuk geometri dengan benar, mengetahui konsep letak dengan benar, dan mengetahui konsep arah dengan benar namun kurang sempurna. Hampir setengahnya (33.3\%) memiliki kecerdasan Visual-Spatial yang cukup. Dikatakan cukup karena mereka tidak dapat menyelesaikan permainan puzzle dengan benar, salah menyebutkan beberapa bentuk geometri yang ditunjukkan, mengetahui konsep letak dan mengetahui konsep arah dengan benar namun kurang sempurna.

Berdasarkan tabel 5.4 dapat diketahui bahwa dari 30 responden dalam penelitian ini setelah dilakukan intervensi berupa permainan puzzle $(16,7 \%)$ responden memiliki kecerdasan VisualSpatial yang sangat baik. Hasil ini meningkat dari hasil sebelumnya hanya $(3,3 \%)$ responden. Hampir seluruhnya $(83,3 \%)$ responden memiliki kecerdasan Visual-Spatial yang baik. Hasil ini meningkat dari hasil sebelumnya hanya (63,3\%) responden. Puzzle adalah permainan konstruktif yang dapat melatih koordinasi mata, tangan dan membutuhkan respon yang tinggi sehingga anak di stimulasi otak kanannya agar kecerdasan Visual-Spatialnya meningkat.

Berdasarkan uji statistik uji t sampel berpasangan menggunakan SPSS For Windows dengan tingkat kemaknaan $(\alpha=0.05)$ diperoleh nilai $\rho=0.000$ maka $\rho<\alpha$, sehingga $H_{0}$ ditolak berarti ada pengaruh permainan puzzle terhadap perkembangan kecerdasan visual-spatial anak usia 4-5 tahun di TK Al-Fath Desa Keboan Anom Gedangan Sidoarjo.

\section{SIMPULAN}

Dari hasil analisa dan pembahasan yang telah dilakukan oleh peneliti maka dapat disimpulkan bahwa :

1. Permainan puzzle anak usia 4-5 tahun di TK Al-Fath Desa Keboan Anom Gedangan Sidoarjo sebagian besar cukup.

2. Perkembangan kecerdasan visualspatial anak usia 4-5 tahun di TK AlFath Desa Keboan Anom Gedangan Sidoarjo sebagian besar baik. 
3. Ada pengaruh permainan puzzle terhadap perkembangan kecerdasan visual-spatial anak usia 4-5 tahun di TK Al-Fath Desa Keboan Anom Gedangan Sidoarjo

\section{DAFTAR PUSTAKA}

Alwi, Hasan.2005.Kamus Besar Bahasa Indonesia Edisi 3.Jakarta:Balai pustaka.

Andrianto, Tuhana Taufiq.2013.Cara Cerdas Melejitkan IQ Kreatif Anak.Jogjakarta:Katahati

Arikunto (2006). Prosedur Penelitian Suatu Teknik Pendekatan Praktik. Jakarta : Rineka Copta

Azwar,

Azrul.2003.Metodologi

Penelitian Kedokteran dan

Kesehatan

Masyarakat.Jakarta:Binarupa Aksara

Choiriyah, Nikmatul.2012.Hubungan Pola Asah Orang Tua dengan Perkembangan Intelektual Anak di TK Unggulan Darul Munir Kelampis Bangkalan.Proposal.Surabaya,

Sekolah Tinggi Ilmu Kesehatan Yayasan Rumah Sakit Islam Surabaya, Tidak Dipublikasikan

Gordon, Claire.2004.Meningkatkan 9 Kecerdasan Anak.Jakarta:PT Bhuana Ilmu Populer

Greene, Laurence.2005.Mengembangkan Multiple

Intelligence.Jogjakarta:Penerbit Andi

Hidayat, A.A.2005.Pengantar Ilmu Keperawatan Anak 1.Jakarta:Salemba Medika

Lwin, May,dkk.2004.Cara

Mengembangkan Berbagai

Komponen

Kecerdasan.Jogjakarta:Indekx

Mukhan, Suhadi.2011.Faktor-Faktor yang Mempengaruhi Perkembangan Intelektual

Anak.http://id.shvoong.com. Tanggal akses 28 Desember 2013

Muthmainnah.2009.Penerapan Multiple Intelligences.http://staff.uny.ac.id. Tanggal akses 14 September 2013
Nursalam.2013.Metodologi Penelitian Ilmu Keperawatan.Jakarta:Salemba Medika

Olivia, Femy.2013.Gembira Bermain Coret-Coret.Jakarta:PT Elex Media Koputindo

Purnomo, Windhu.2007.Handout Biostatistika.Surabaya,FKM Unair

Sefrina, Andin.2013.Deteksi Minat Bakat Anak Optimalkan 10 Kecerdasan pada Anak.Jogjakarta:Media Pressindo

Sugiyono.2012.Metode Penelitian Kuantitatif, Kualitaif, dan $R \& D$.Bandung:Alfabeta

Surya, Sutan.2007.Melejitkan Multiple Intelligence Anak Usia Dini.Jogjakarta:Penerbit Andi

Utami, Sri, dkk.2008.Bermain Lego Meningkatkan Perkembangan Kognitif Anak Usia Prasekolah (4-5 tahun).Jurnal Ners Vol.3 Nomor 2 Oktober 2008.Progam Sudi Ilmu Keperawatan Fakultas Keperawatan Unair

Winsky.2009.Be Smarter in One Week.http://winsky.wordpress.com.T anggal 23 Desember 2013 